\title{
Parent-Student Interactions and Parent School Relationships as Predictors of Academic Achievement of Students in Basoliben Woreda Secondary School, North West Ethiopia
}

\author{
Demelash Abewa*, Hayimro Edemealem \\ Department of Statistics, Debre Markos University, Debre Markos, Ethiopia \\ Email address: \\ demestat21@gmail.com (D. Abewa), hayimroe@gmail.com (H. Edemealem) \\ *Correspondence author
}

\section{To cite this article:}

Demelash Abewa, Hayimro Edemealem. Parent-Student Interactions and Parent School Relationships as Predictors of Academic Achievement of Students in Basoliben Woreda Secondary School, North West Ethiopia. Science Research.

Vol. 7, No. 4, 2019, pp. 44-50. doi: 10.11648/j.sr.20190704.11

Received: February 21, 2019; Accepted: April 4, 2019; Published: October 15, 2019

\begin{abstract}
Academic achievement is a comprehensive concept which requires an in depth investigation of the real world and even the students accomplishment in school including progress in core subjects. The purpose of this study is to assess the relationships of parent student interaction, parent school relations and academic achievement in Basoliben woreda. To achieve this objective a sample of 366 students has taken and self-administered questionnaires were distributed through the selected respondents. Both descriptive and multiple linear regression model were employed. The result shows that the average mark of secondary school student is 67.3286 with maximum of 98.3 and a minimum of 45 . There is also average mark difference between male students and female students. From multiple linear regression result, it is evident that gender, Age, distance from the parent's house to school, parental support, student taking alcohol, parent use alcohol and money receive from parent for entertaining purpose have a significant effect on academic achievement of secondary school students. From the result of this study, we concluded that there is also low parent- school relationship in the study area and it affects the academic achievement of students. Emphasis should be given to improve the academic performance of female students through adjusting special support which may allow female students perform well, Parent should be work in the ground to improve students' academic achievement.
\end{abstract}

Keywords: Academic Achievement, Basoliben, Mark of Student, Multiple Linear Regression, Secondary School

\section{Introduction}

\subsection{Background of the Study}

Academic achievement is a comprehensive concept which requires an in depth investigation of the real world in school including progress in core subjects- mathematics, science, language and social studies.

A higher level of involvement is achieved further along the range where parents take more active part in the activities of associations, perhaps help in the classroom, and assist in other work. In this way the focus of their relationships with the school widens from that of the parent concerned with his or her child's education. People from differing professional background may have different values and attach a range of meanings to terms [1].

Motivates parents show greater interest in their children's education. In some cases, the functioning of local education offices was financed by communities [2]. According to De Grauwe, A., et al., the involvement of parents, teachers, local councilors and education officials in school management can help to promote decision-making at school level, which improves the quality of schooling and students' achievement [3]. Parents play an important role in leading to operative growth and development of their children [4]. In schools, whatever problems that children go through regarding academics and other areas, they normally communicate to their parents. Parents are sources of security, encouragement 
and help their children in providing solutions to their problems.

When students are unable to achieve the desired grades, then instead of getting angry on them, the teachers and parents need to make provision of help and assistance. They should motivate the students and encourage them to do well in future. They need to understand their weaknesses and help them. When students find certain areas difficult to learn, then teachers should repeat the concepts; provide them class and homework assignments, so that they are able to acquire complete understanding of the concepts [5].

In the wide spread affluence of the post-world-war second period, parents came under much greater to assist by providing a materially enriched home environment, but were only expected to become significantly engaged in discussion of their children's academic achievement if schools identified problem [6].

Parental involvement may have very essential in schoolbased activities of their children. These activities may involve contacts with teachers, checking the attendance of children in school, monitoring their activities in school, checking their periodical academic progress reports. All these things might be very helpful in higher level academic achievements of children. Parents become more concerned about the learning opportunities that secondary schools provide. As children move from the middle grades to the secondary school, parents also crystallize their educational expectations for their children. As students complete school education, parents become increasingly concerned about their teen's further education and about the effects of secondary school programs on postsecondary opportunities [7].

Experience tells us that parents are less involved in Ethiopia, and most parents are less involved in schools and teachers less regard parental involvement except for fund raising. But recently there is a drive in parent-school relationships.

The impact of parental involvement on academic achievement is not yet well studied. Traditionally parentchild interaction in our country is more of authoritarian type. But recently, due to the emergence of literate parents, the interaction is becoming more frequent and purposeful.

\subsection{Statement of the Problem}

Education is a societal activity. Teachers, parents, school administration staff, the parent teacher association, the government, NGOS and whole society are the common and well known stake holders. The participation of stakeholders for the improvement of students' academic achievement has become improved from time to time. But yet there is a problem of connecting the school community and the society.

Parental involvement in education of their children has been significantly linked with the quality of education and academic achievement of children. It may further contribute in mitigating the mass level failure of students in examinations that may indirectly cause wastage of parents' own resources as well as the public expenditures for imparting formal education in schools. For example, 50 per cent students fail in secondary level education examinations means loss of half of the public budget spent on educating the students and parents expenditures for purchasing books and other allied expenses for educating their children. Besides bearing the financial expenses of educating children, parental involvement in academic activities of their children may not only save personal and public spending but also it would be contributive in improving the quality of education of children at individual and national level.

The quality of teaching learning process in Ethiopian schools is very low [8]. Similarly, in the national learning assessment of grade 10 and 12 students, the academic achievement of the students measured by the mean score of the five subjects namely English, Mathematics, Biology, Chemistry and Physics was found to be less than the minimum requirement $(50 \%)$ achievement level set by the Education and training policy of Ethiopia. That is the national mean score (the average of what the students scored in five subjects) was only $35 \%$ for grade 10 and $47.8 \%$ for grade 12 [9].

Most secondary schools of Basoliben woreda are built around urban areas. Because of this, there is a difficulty of strengthening parent-student interaction and parent-school relationship which in turn negatively affects students' academic achievement i.e. most students live in dormitory and meet their parent very rarely and also the distance of the school from parent residence and lack of transport access hinder the interaction, parents altitude towards school is yet its early stage sending children to school is enough for effective academic achievement as they explain in different context. They seem to believe that improving academic achievement can be raised only with the effort of teacher and other school community.

\subsection{Objectives of the Study}

\subsubsection{General Objective}

The scope of the study is bounded on assess the relationships of parent, student interaction, parent school relations as predictor students' academic achievement with reference to secondary schools in Basoliben woreda, East Gojjam Zone, Ethiopia.

\subsubsection{Specific Objectives}

1. To show the average mark of secondary school students.

2. To examine effect of parent student interactions on students' academic achievement at secondary school.

3. To assess the effect of parent-school relations on academic achievement of secondary school students.

\subsection{Research Questions}

The main leading questions of the study are:

1. What is the average score of secondary school students?

2. What does the interaction of parents with student and relationship of parents with schools look like?

3. Does parent student interaction and parent school relationship significantly affect students' academic achievement? 


\section{Research Methodology}

\subsection{Data and Sampling Design}

The study uses both primary and secondary sources of data. Primary data have been collected from the selected sample students from each selected kebele trough questionnaire and structured interview. Secondary data or List of the selected samples from each kebele has been acquired from basoliben woreda. Because of the heterogeneity nature of the population included in the study the representative sample students selected from each selected kebele through stratified sampling techniques. The study assumes each selected kebele as strata and sample have been selected from each stratum. Among 4411 total number of secondary school students the representative samples were 366.

\subsection{Statistical Model}

In order to address the objective of the study, in addition to descriptive statistics, the econometric models would also employ, it would be used to estimate the relationship between the variables (academic achievement and predictor variable) using the parameter of the variables.

Multiple Linear Regression Model

Regression analysis is broadly defined as a statistical tool for the investigation of relationships between variables. Multiple regressions allow researchers to examine the effect of more than one explanatory variable on response variables. Linear regression can be used to examine how much a particular set of independent variables can explain the variability in the continuous outcome sufficiently. The response variable (academic achievement) is a continuous variable. In the model of multiple linear regression, the regress and (which can be either the endogenous or a transformation of the endogenous variables) is a linear function of $\mathrm{k}$ regressors corresponding to the explanatory variables or their transformations and of a random disturbance or error [10]. The generalized model for the multiple linear regression models is:-

$$
\mathrm{Y}_{\mathrm{i}}=\beta_{0}+\beta_{1} \mathrm{X}_{1}+\beta_{2} \mathrm{X}_{2}+\beta_{3} \mathrm{X}_{3}+\ldots+\beta_{\mathrm{k}} \mathrm{X}_{\mathrm{k}}+\epsilon_{\mathrm{i}}
$$

$\mathrm{Y}_{\mathrm{i}}=$ predicted value of academic achievement given that value of the independent variables $\left(\mathrm{x}_{1}, \mathrm{x}_{2}, \mathrm{x}_{3}, \ldots\right.$ etc. $)$

$\mathrm{X}_{\mathrm{k}}=\mathrm{k}_{\mathrm{th}}$ factor that affect academic achievement of the students

$\beta_{\mathrm{k}}=\mathrm{k}^{\text {th }}$ population parameters to be estimated

$\mathrm{C}_{\mathrm{i}}=$ errors terms or other factors not included in this study Assumption of Multiple Linear Regressions

1. The error term has constant variance

2. The error terms are uncorrelated. That is, no serial correlation (serial independence of the Ei's. it also implies that the covariance error terms became zero. i.e. $\operatorname{cov}(\mathrm{Ci}, \mathrm{\epsilon j})=0$

3. Errors are normally distributed. i.e. $\operatorname{CiN}\left(0, \sigma^{2}\right)$

4. No collinearity between independent variables.

5. X's -are independent (no Multicolinearity) each other.
The most popular method of estimating the multiple linear regression parameters $(\beta)$ is least square method. Least squares method is a method that obtains an estimate of $\beta$ which minimizes the sum of square deviation of the observed values of the dependent variable (Y) from its function.

$$
\mathrm{E}(\mathrm{Y})=\mathrm{X} \beta \text {. }
$$

\section{Hypothesis Testing}

i. Test of Overall Model Parameter

Step 1: The overall goodness of the model (the model is not significant) vs. H1: at least one of regression coefficient different from zero (the model is significant).

Step 2: Specify $\alpha$ level of significant.

Step3: Test statistics.

$\mathrm{f}_{\mathrm{cal}}=\mathrm{MSR} / \mathrm{MSE}$, where $\mathrm{MSR}=$ the regression mean square with p-1 degree of freedom, MSE=mean square of error with $\mathrm{n}-\mathrm{p}$ degree of freedom.

Step 4: Decision: If $\mathrm{f}_{\text {cal }}>\mathrm{f}_{\text {tab }}$ or $\mathrm{p}$ value $<\alpha$ then Ho will be rejected at a given significance level.

Step 5: give conclusion based on the above decision.

ii. Test of Individual Parameter

Step 1: Ho: $\beta \mathrm{i}=0$ vs. H1:s $\mathrm{i} \neq 0 . \mathrm{i}=1,2,3 \ldots \ldots . \mathrm{p}$ or Ho: the variable has no significant effect on the response variable H1: the variable has a significant effect on the response variable.

Step 2: Specify $\alpha$ level of significant.

Step3: Test statistics For Small sample $(n<30), t_{\text {cal }}$ $=\beta / \operatorname{se}(\beta)$.

Step 4: Decision $t_{\text {cal }}>t_{\text {tab }} n-p$ or $p$ value $<\alpha$, then reject Ho at a given significant level $(\alpha)$.

Step 5: give conclusion based on the above decision.

\subsection{Variables of the Study}

Variables considered in this study are taken mostly based on earlier studies at the global and national level. In this study, the potential determinant factors are expected to be correlated with academic achievement of secondary students. Those variables considered in this study are classified as: dependent and explanatory or predictor variables. The dependent variable of interest for this study was collected from Basoliben secondary schools registrar office. The following independent variables included in the study are:

Gender of student

Student support by parent

Take alcohol

Parents assign somebody to help student

Distance from home to school

Parent take alcohol

My parent often ask teachers about my talent

Age of student

Special talent

Support money from parent

Parent education level

School invites parents to attend meeting

Fail in exam discuss with parent and teacher 


\section{Results and Discussions}

\subsection{Descriptive Results}

Descriptive result of the study shows that the average mark of secondary school student is 67.3286 with maximum of 98.3 and a minimum of 45 marks.

Table 1 below illustrates that t-test obtained on students' academic achievement and gender of students is $\mathrm{t}=10.058$ with $p$-value 0.000 which is less than alpha $=0.05$ implying that being maleness significantly and positively related to academic performance than females Average mark of the student. After analyzing the result by using independent $\mathrm{T}$ test, the result shows that there is a significance difference between student support by their parent and non support students on academic achievement of secondary school students. The average mark of student support by parent was 69.8947 and non-supported, has a mean value of 65.3882 . This shows that student support by their parent has a higher score than the student not support of their parents. The average score of students, who take tutorial and do not take tutorial, was 75.895 and 64.1081 respectively. This indicates that students taking tutorial have better academic achievement than students who not taking the tutorial.

Table 1. The relation between students' parent characteristics and student achievement.

\begin{tabular}{|c|c|c|c|c|c|}
\hline Variable & & Mean mark & Std deviation & $\mathbf{t}$ & P value \\
\hline \multirow{2}{*}{ Gender of student } & male & 71.10 & 10.96815 & \multirow{2}{*}{10.058} & \multirow{2}{*}{$0.000 * * *$} \\
\hline & female & 61.2976 & 4.68437 & & \\
\hline \multirow{2}{*}{ Tutor } & yes & 75.895 & 11.74993 & \multirow{2}{*}{11.403} & \multirow{2}{*}{$0.000 * * *$} \\
\hline & No & 64.1081 & 7.42171 & & \\
\hline \multirow{2}{*}{ Support by parent } & yes & 69.8947 & 11.38649 & \multirow{2}{*}{4.226} & \multirow{2}{*}{$0.000 * * *$} \\
\hline & no & 65.3882 & 8.83582 & & \\
\hline Parents job & agriculture & 67.99825 & 9.97403 & 4.529 & $0.000 * * *$ \\
\hline \multirow{2}{*}{ Parent buy books } & yes & 68.0775 & 10.41215 & \multirow{2}{*}{3.910} & \multirow{2}{*}{$0.000 * * *$} \\
\hline & no & 61.6953 & 6.73777 & & \\
\hline
\end{tabular}

Note: $* * *$ show significance at $5 \%$ levels.

Table 2 illustrates the t-test obtained on the average mark of students with school invite parents to attend meetings, my parent often asks teachers about my talent and discusses parenting with the teacher have $\mathrm{p}$-value of $0.484,0.263$ and 0.000 respectively. Based on the p-value there is no average mark differences among students, either the parents of students' participate in school meeting or not participate in school meeting. In addition to this there is no average mark difference among students, either students' parent ask teacher about students' special talent or not parent ask teacher about students' talent but there is a significance average mark difference among students when parent and teacher discuss and not discuss.

Table 2. The relation between students' parent and school interaction on students' academic achievement.

\begin{tabular}{|c|c|c|c|c|c|}
\hline Variable & & Mean mark & Std deviation & $\mathbf{t}$ & P value \\
\hline \multirow{2}{*}{ School invite parents to attend meeting } & yes & 67.5464 & 11.30741 & & \multirow{2}{*}{0.484} \\
\hline & No & 66.6800 & 6.11700 & 0.701 & \\
\hline \multirow{2}{*}{$\begin{array}{l}\text { My parent often ask teachers about my } \\
\text { talent }\end{array}$} & yes & 66.4944 & 10.12998 & \multirow{2}{*}{-1.121} & \multirow{2}{*}{0.263} \\
\hline & No & 67.7612 & 10.30883 & & \\
\hline \multirow{2}{*}{ Discuss parent with teacher } & yes & 73.5784 & 11.29861 & \multirow{2}{*}{9.992} & \multirow{2}{*}{$0.000 * * *$} \\
\hline & No & 63.7188 & 7.53811 & & \\
\hline
\end{tabular}

Note: $* * *$ show significance at $5 \%$ levels.

Education level of parent categorizes as illiterate, primary, secondary and college and above. In this study the highest education level was college and above. The result of one-way ANOVA (Table 3) the P-value is 0.000 . This result shows that there is a significant difference between the Education level parents on the academic achievement of their child. To show which categories of educational level mean different from the other, the researcher conducted multiple comparisons using the LSD method. The result shows that there is no students' average mark difference between their parent education level illiterate and primary school but the rest pair of education level of parent has a significance difference in academic achievement of secondary school students.

Table 3. Average mark of students with parent education level.

\begin{tabular}{lllll}
\hline & Sum of square & Df & Mean square & F \\
\hline Between group & 3580.184 & 3 & 1193.395 & 12.421 \\
With in group & 34781.647 & 362 & 96.082 & $0.000 * * *$ \\
Total & 38361.830 & 365 & & \\
\hline
\end{tabular}

Note: $* * *$ show significance at $5 \%$ levels. 


\subsection{Econometrics Results}

This section of the paper presents the statistical significance of determinant factors of academic achievement of secondary school students obtained from linear regression (OLS).

The model satisfy the assumption of linearity, the assumptions of homoscedasticity or constant variance of the error term, no perfect multi co linearity among independent variables, there not be exists specification error / no functional miss specification, the assumption of normality, no serial auto correlation among successive values of the error term. Since the model satisfies the assumption of OLS, we can estimate the effect of such determinant variables on student's academic performance.

The regression coefficient table or t-test of regression analysis shows the effect of each predictor variable on the response variable. The refereeing significance level of each predictor variables shows that from nominated 10 independent variables 8 of them have highly significant effects on the student's academic performance. The fitted multiple linear regression equation is given by:

$$
\begin{gathered}
\mathrm{Yi}=124.733-7.71893 \mathrm{X}_{1}-2.5993 \mathrm{X}_{2}-0.1733896 \mathrm{X}_{3}-3.21468 \mathrm{X}_{4^{-}} \\
2.787806 \mathrm{X}_{5}+1.691034 \mathrm{X}_{6}+7.643026 \mathrm{X}_{7}-4.705885 \mathrm{X}_{8^{-}} \\
6.684383 \mathrm{X}_{9}+5.169712 \mathrm{X}_{10}
\end{gathered}
$$

Where $\mathrm{Yi}$ is academic performance and $\mathrm{X} 1$ is Sex of student, $\mathrm{X} 2$ is Age of student, $\mathrm{X} 3$ is distance from school to home, X4 is Parent job, X5 is Support, X6 is Have special talent, $\mathrm{X} 7$ is Parent take alcohol, $\mathrm{X} 8$ is Money offer from parent, $\mathrm{X} 9$ is Get tutorial from parent and $\mathrm{X}_{10}$ isStudent take alcohol. The set of predictor variables listed in the regression coefficient table, and the regression coefficients $\beta \mathrm{i}$ for each predictor variable also given in table 5. From the table it has shown that students' gender is highly significant with $\mathrm{B}=$ 7.71893 and $\mathrm{p}=0.000$. This indicates that when holding the effect of other things remain constant male students' average mark greater than female students average mark by 7.71893 . The regression held in favor of male students and the result also shows a gender difference has a significant effect on students' average mark. Male students perform well than female students. This could be attributed to the fact that Ethiopian female traditionally have suffered socio-cultural and economic discrimination and have had fewer opportunities than male for personal growth and education. This result contradicts the result of [11], who found that male and female secondary school students were found to have the same level of academic achievement.

Age of student is significant negative impact on student academic performance. The value of the coefficient $B$ of a variable age is -2.5993 , it entails that holding the effect of other things remain constant if a student's age increased by one year a student being a success or average mark decreased by 2.5993. This finding confirms with the finding of [12], who found that an increase in one unit of the age of a candidate will decrease performance in Kenya Certificate of
Secondary Education.

Distance from students' parent home to their secondary school has a statistical significance affect the academic achievement of students with $\mathrm{p}$ value $=0.008$, which is less than 0.05. This means that the distance from a student's parent home to school increase by one kilometer, the average mark of secondary school students' scores decrease by 0.173896 unites holding the other variables constant. This could be students are vulnerable to violence on their long and hazardous journey to or from school and it has a direct impact on their academic achievement.

Behaviors of students in not taking alcoholic, drug positively significant determine average mark or academic performance of secondary school students and the variable is significant at the $5 \%$ level of significance. The value of the coefficient B for a variable Student take alcohol is 5.163712, it entails that holding the effect of other things remain constant if students not addictive by alcohol increase their success or average mark of 5.163712 unites than those who addictive by alcohol. This finding is comparable with earlier study of [13].

Student not take money from their parent for entertaining purpose has a negative significance, impact on the student's academic performance (average mark). The value of the coefficient $B$ for a variable Money take from parent is 4.705885 , it entails that holding the effect of other things remain constant, if students not take money from their parent for entertain purpose decrease their success or average mark by 4.705885 unites than those who take money from their parent for entertain purpose. This finding confirm with the finding of [13]. This implies that get money may lead to improve students' academic achievement. In fact if the students get enough money, they may invest this money for recreation purpose. This may have a direct impact on their academic achievement.

Parental not support (involvement) has a negative and significance effect on the academic achievement of students. The value of the coefficient $B$ for a variable support is2.787808, it entails that holding the effect of other things remain constant if students not get support from their parent decreased their success or average mark by 2.787808 unites than those who get support from their parent. Parental involvement takes many forms including good parenting in the home, including the provision of a secure and stable environment, intellectual stimulation, parent-child discussion, good models of constructive social and educational values and high aspirations relating to personal fulfillment and good citizenship; contact with schools to share information; participation in school events; participation in the work of the school; and participation in school governance. Parental involvement is strongly positively influenced by the student's level of attainment: the higher the level of attainment, the more parents get involved or support. 
Table 4. Regression coefficient result.

\begin{tabular}{llllll}
\hline Covariate & Categories & $\widehat{\boldsymbol{\beta}}$ & S.E $(\widehat{\boldsymbol{\beta}})$ & $\mathbf{t}$ & $\mathbf{p}>$ Itl \\
\hline Sex of student & Female & -7.71893 & 0.9772197 & -7.90 & $0.000^{* * *}$ \\
Age of student & Male (ref) & - & - & - & - \\
distance from school to home & age & -2.5993 & 0.4718161 & -5.51 & $0.000^{* * *}$ \\
Parent job & distance & -0.1733896 & 0.0646624 & -2.68 & $0.008^{* * *}$ \\
& trade & -3.21468 & 1.769262 & -1.82 & 0.070 \\
Supportby parent & agriculture (ref) & - & - & - & - \\
& No & -2.787806 & 0.9201261 & -3.03 & $0.003^{* * *}$ \\
Have special talent & Yes (ref) & - & - & - & - \\
& No & 1.691034 & 0.8727571 & 1.94 & 0.0053 \\
Parent take alcohol & Yes (ref) & - & - & - & - \\
Money take from parent & No & 7.643026 & 1.486148 & 5.14 & $0.000^{* * *}$ \\
& Yes (ref) & - & - & - & - \\
Get tutorial from parent & No & -4.705885 & 0.8252614 & -5.70 & $0.000^{* * *}$ \\
Student take alcohol & Yes (ref) & - & - & - & - \\
constant & No & -6.684383 & 1.02194 & -6.54 & $0.000^{* * *}$ \\
\hline
\end{tabular}

Note: *** and ref show significance at $5 \%$ levels, and show reference group respectively.

\section{Conclusion and Recommendation}

The study attempted to investigate parent-student interactions and parent-school relationships as predictors of academic achievement with reference to Basoliben woreda secondary Schools. In view of the research questions, the main finding of the study is that parent supports their student has a significant effect on the academic achievement of the student. There is also low parent- school relationship in the study area and it affects the academic achievement of students. From the econometric model age, distance from parent's house to school, parental support, student taking alcohol, parent use alcohol, students' source of income, money receive from parent for entertain purpose and student help parents have a significance effect on academic achievement of secondary school students, whereas parents' job, parental education level and student having special talent have no significance effect on academic performance.

From the result of the study the following recommendations were forwarded:

1. Emphasis should be given to improve the academic performance of female students through adjusting special support which may allow female students perform well.

2. The parent should provide money for their child for entertaining purpose to improve students' academic performance.

3. A parent should be working on the ground to improve students' academic achievement.

4. School leaders should be prepared meeting for students' parent to discus about the academic issue of their students.

5. Office of education should be preparing educational panel in each kebele in the Basolibenworeda.

\section{References}

[1] Shaeffer, S., Partnerships and participation in basic education: A series of training modules and case study abstracts for educational planners and managers. 1994: International Institute for Educational Planning.

[2] Dunne, M., K. Akyeampong, and S. Humphreys, School processes, local governance and community participation: understanding access. 2007.

[3] De Grauwe, A., et al., Strengthening local actors: the path to decentralizing education. Kenya, Lesotho, Uganda. IIEP UNESCO, Paris, 2011.

[4] Lee, J.-S. and N. K. Bowen, Parent involvement, cultural capital, and the achievement gap among elementary school children. American educational research journal, 2006. 43 (2): p. 193-218.

[5] Srinivas, P. and S. Venkatkrishnan, Factors affecting scholastic performance in school children. IOSR Journal of Dental and Medical Sciences, 2016. 15 (7): p. 47-53.

[6] Lareau, A., Linking Bourdieu's concept of capital to the broader field. Social class, poverty, and education, 2001: p. 77-100.

[7] Catsambis, S. and J. E. Garland, Parental Involvement in Students' Education during Middle School and High School. Report No. 18. 1997.

[8] Desta, D., D. Chalchisa, and G. Lemma, School-based continuous teacher professional development in Addis Ababa: An investigation of practices, opportunities and challenges. Journal of International Cooperation in Education, 2013. 15 (3): p. 77-94.

[9] Gebrekidan, Z., Ethiopian National Assessment of Grade 10 and 12 students. National Agency for Examination, 2010. 
[10] Uriel, E., 3 Multiple linear regression: estimation and properties. parameters, 2013.1 (2): p. 3.

[11] Pawar, S., A STUDY OF ACADEMIC ACHIEVEMENT MOTIVATION AMONG SECONDARYSCHOOL STUDENTS. Scholarly Research Journal for Interdisciplinary Studies, 2017. 4 (36): p. 6646-6651.
[12] Waseka, E. and E. Simatwa, Student Factors Influencing Academic Performance of Students in Secondary Education in Kenya: A Case Study of Kakamega County. Educational Research, 2016. 7: p. 72-87.

[13] Yigermal, M. E., The Determinants of Academic Performance of under Graduate Students: In the Case of Arba Minch University Chamo Campus. Online Submission, 2017.3 (4): p. 35-42. 